\title{
Mekanisme Koping Berhubungan dengan Tingkat Depresi pada Mahasiswa Tingkat Akhir
}

\author{
Muhammad Agung Krisdianto ${ }^{1}$, Mulyanti ${ }^{2}$ \\ 1,2 Sekolah Tinggi IImu Kesehatan Alma Ata Yogyakarta \\ Jalan Ringroad Barat Daya No 1 Tamantirto, Kasihan, Bantul, Yogyakarta
}

\begin{abstract}
Abstrak
Mahasiswa tingkat akhir yang mekanisme koping individunya maladaptif akan sangat mudah sekali mengalami depresi. Minimnya pengetahuan tentang cara mencegah dan mengatasi akan dapat mengakibatkan dampak yang fatal yaitu bunuh diri. Penelitian kuantitatif induktif dengan rancangan cross sectional ini bertujuan mengetahui hubungan mekanisme koping dengan tingkat depresi pada mahasiswa tingkat akhir Program Studi Pendidikan Ners Perguruan Tinggi Alma Ata Yogyakarta. Pengambilan sampel dengan metode total sampel, jumlah sebanyak 47 mahasiswa. Analisis uji menggunakan uji Chi-Square. Hasil Uji Chi-Square variabel mekanisme koping dengan usia $(p=0,408)$, jenis kelamin $(p=0,103)$, tempat tinggal $(p=0,057)$ dan tingkat depresi $(p=0,000)$. Ada hubungan yang bermakna antara mekanisme koping dengan tingkat depresi $(p<0,05)$, tidak ada hubungan yang bermakna antara mekanisme koping dengan usia, jenis kelamin, dan tempat tinggal $(p>0,05)$.
\end{abstract}

Kata Kunci: mahasiswa tingkat akhir, mekanisme koping, tingkat depresi

\section{Coping Mechanism Related with Level of Depression in Final Students}

\begin{abstract}
Final year students whose individual maladaptive coping mechanisms would be very easy to get depressed. Less of knowledge about how to prevent and treat depression may result in fatal impact that is suicide. This inductive quantitative research with cross sectional design was aimed to know the relationship between mechanism koping with the level of depression in the last year student of the level of education ners study program college Alma Ata Yogyakarta. Samples were obtained by total sample technique which consisted of 47 respondents. Analysis test used Chi-Square test. The result of this research showed that there was a significant relationship between coping mechanisms at the level of depression $(p<0.05)$ however there was no significant relationship between coping mechanisms with age, gender, and place of residence $(p>0.05)$.
\end{abstract}

Keywords: final students, coping mechanisms, level of depression

Info Artikel:

Artikel dikirim pada 7 Juni 2015

Artikel diterima pada 7 Juni 2015

\section{PENDAHULUAN}

Mahasiswa dalam perkembangannya ialah sebagai remaja akhir atau dewasa awal yaitu usia 18-21 tahun dan 22-24 tahun(1). Mahasiswa akan mengalami masa kuliah di suatu universitas selama minimal tiga atau empat tahun, dan akan mengakhiri masa kuliahnya dengan menyusun skripsi sebagai syarat kelulusan untuk mendapat gelar sarjana. Fase ini biasanya membuat mahasiswa menjadi stress bahkan depresi(2).
American College Health Association-National College Health Assesment (ACHA-NCHA) pada tahun 2011 meneliti perjalanan mahasiswa dari tahun ke dua hingga empat diberbagai institusi pendidikan di Amerika, dan menemukan ada 30\% dari mahasiswa yang menyatakan bahwa "merasa tertekan hingga tidak dapat berbuat apa-apa" terutama pada tingkat akhir. Banyak mahasiswa tingkat akhir yang mengalami depresi tetapi tidak paham harus kemana untuk mengatasinya(3). 
Kurangnya pengetahuan tentang cara mengatasi masalah depresi akan menyebabkan kejadian depresi yang lebih besar, World Health Organization (WHO) mengungkapan lebih dari 350 juta penduduk dunia saat ini mengidap depresi(4). Berdasarkan data Riset Kesehatan Dasar (Riskesdas) tahun 2007, di Indonesia prevalensi gangguan mental emosional seperti kecemasan dan depresi pada dewasa (termasuk dewasa muda) berjumlah kurang lebih 1.740 .000 orang(5). Belum ada angka pasti tentang mahasiswa yang depresi di Indonesia, tetapi ada beberapa contoh yang menjadikan depresi merupakan hal serius, salah satunya yaitu kasus mahasiswa suatu perguruan tinggi di Sumatra Utara berinisial FAP 23 tahun, bunuh diri akibat deadline skripsi(6).

Selain BK dan orang tua, poli klinik yang berfokus pada kesehatan jiwa remaja merupakan sebuah solusi. Pemerintah sebenarnya berharap hal ini dapat meminimalisasi angka depresi pada mahasiswa yang disebabkan oleh proses perkuliahan dan penyusunan skripsi. Indonesia memiliki 84 rumah sakit jiwa dengan kapasitas 7.700 tempat tidur, dan beberapa poli klinik serta konsultasi kejiwaan(7), namun diakui oleh Direktur Kesehatan Jiwa Kementerian Kesehatan Eka Viora bahwa pelayanan kejiwaan di Indonesia masih minim dikarnakan dokter-dokter kesehatan jiwa belum memadai di seluruh Indonesia(8).

Depresi pada mahasiswa tingkat akhir dalam proses skripsi memang merupakan suatu fenomena yang harus diantisipasi. Depresi itu sendiri ialah keadaan psikologis yang patologis. Dampak lain dari depresi ialah adanya penurunan semangat bekerja, bergaul, dan nafsu seksual(9). Kejadian depresi pada mahasiswa tingkat akhir pada proses skripsi dapat dipengaruhi oleh mekanisme koping individu. Mekanisme koping itu sendiri merupakan cara yang dilakukan individu dalam menyelesaikan masalah(10).

Mekanisme koping itu dibagi menjadi dua, yaitu adaptif dan maladaptif. Mekanisme koping adaptif merupakan hal yang mendukung fungsi integrasi. Mekanisme koping adaptif inilah yang diharapkan mampu mengurangi resiko angka kejadian depresi pada mahasiswa tingkat akhir yang sedang menjalani proses skripsi. Sebaliknya mekanisme koping maladaptif ialah hal yang menghambat fungsi integrasi(11). Beberapa masalah yang dihadapi mahasiswa tingkat akhir ialah program yang tak sesuai, penugasan materi, tidak paham dengan materi, pendapatan keluarga di bawah rata-rata, dosen pembimbing, dan proses skripsi(12).

Berdasarkan studi pendahuluan yang dilakukan pada Perguruan Tinggi Alma Ata Yogyakarta di Mahasiswa Tingkat Akhir Program Studi Pendidikan
Ners angkatan 2011 secara observasional, semua mahasiswa lebih senang melampiaskan perasaannya ke dalam media sosial, menyendiri, meluapkan emosi secara berlebihan dan menangis. Hasil kuesioner 7 dari 8 orang mengalami minimal depresi (2 orang mengarah depresi ringan), 1 orang depresi ringan. Jumlah mekanisme koping yang digunakan adalah 3 orang dengan koping adaptif, dan 5 orang dengan koping maladaptif. Oleh karena itu peneliti tertarik untuk menjadikan topik ini sebagai bahan penelitian untuk meminimalkan depresi khususnya pada mahasiswa dan mahasiswi yang mempersiapkan diri untuk proses skripsi. Tujuan penelitian ini untuk mengetahui hubungan mekanisme koping dengan tingkat depresi, tingkatan depresi, mekanisme koping yang dilakukan, hubungan mekanisme koping dengan usia, hubungan mekanisme koping dengan jenis kelamin, dan hubungan mekanisme koping dengan tempat tinggal pada mahasiswa tingkat akhir Program Studi Pendidikan Ners Perguruan Tinggi Alma Ata Yogyakarta.

\section{BAHAN DAN METODE}

Jenis penelitian ini merupakan penelitian Kuantitatif Induktif, dengan rancangan cross sectional. Penelitian ini dilaksanakan di Perguruan Tinggi Alma Ata Yogyakarta. Penelitian ini dilaksanakan pada bulan Desember 2014 dan Januari 2015.

Variabel bebas dalam penelitian ini adalah mekanisme koping. Variabel terikat dalam penelitian ini adalah tingkat depresi. Jumlah populasi yaitu 47 orang mahasiswa. Sampel 47 orang, teknik sampling menggunakan total sampling.

Kuesioner yang digunakan dalam penelitian ini ada dua, yaitu the beck depression inventory (BDI) II dan Mekanisme Koping yang diadopsi dari Indra. Intepretasi BDI II dibagi menjadi empat tingkatan, antara lain: minimal depresi dengan rentang skor $0-13$, depresi ringan dengan skor 14-19, depresi sedang skor 20-28, dan depresi berat skor 29-63. Nilai $<4$ biasanya ada kemungkinan untuk menyangkal depresi (faking good)(13). Intepretasi mekanisme koping menggunakan skala Likert untuk pertanyaan positif digunakan penilaian: [4] Selalu, [3] Sering, [2] Jarang, [1] Tidak Pernah, sedangkan untuk pertanyaan negative: [1] Selalu, [2] Sering, [3] Jarang, [4] Tidak Pernah(14).

\section{HASIL DAN BAHASAN}

Responden dalam penelitian ini adalah mahasiswa tingkat akhir Program Studi Pendidikan Ners Perguruan Tinggi Alma Ata Yogyakarta 
yang memenuhi standar kriteria. Secara lengkap karakteristik responden meliputi, jenis kelamin, usia, dan tempat tinggal akan disajikan dalam Tabel 1.

\section{Tabel 1. Distribusi Frekuensi Karakteristik Responden Mahasiswa Tingkat Akhir Program Studi Pendidikan Ners Perguruan Tinggi Alma Ata Yogyakarta}

\begin{tabular}{lcc}
\hline \multicolumn{1}{c}{ Variabel } & $\mathbf{f}$ & $\%$ \\
\hline $\begin{array}{l}\text { Jenis Kelamin } \\
\text { Laki-laki }\end{array}$ & 18 & 39,1 \\
Perempuan & 28 & 60,9 \\
Usia (Tahun) & & \\
20 & 6 & 13,0 \\
21 & 24 & 52,2 \\
22 & 9 & 19,6 \\
23 & 5 & 10,9 \\
24 & 1 & 2,2 \\
40 & 1 & 2,2 \\
Tempat Tinggal & & \\
Kos, Kontrakan, Asrama & 39 & 84,8 \\
Orang Tua & 7 & 15,2 \\
Total & 46 & 100,0 \\
\hline
\end{tabular}

Sumber: Data Primer Tahun 2014

Berdasarkan Tabel 1, menunjukan bahwa karakteristik responden kelompok jenis kelamin yaitu sebagian besar adalah perempuan sebanyak 28 orang $(60,9 \%)$, rata-rata responden berusia 21 tahun sebanyak 24 orang $(52,2 \%)$ dan sebagian besar responden bertempat tinggal tidak dengan orang tua (kos, kontrakan, asrama) sebanyak 39 orang $(84,8 \%)$.

Mahasiswa dalam perkembangannya ialah sebagai remaja akhir atau dewasa awal yaitu usia 18-21 tahun dan 22-24 tahun(1). Berdasarkan teori dan hasil penelitian menunjukan bahwa mahasiswa akhir merupakan seseorang yang berusia minimal 18 tahun dan maksimal 24 tahun.

Hasil analisis kategori jenis kelamin menggambarkan, sebagian besar responden berjenis kelamin perempuan sebanyak 28 orang (60,9\%). Jumlah responden perempuan lebih banyak dibanding laki-laki di Fakultas IImu Kesehatan, Jurusan Keperawatan, Universitas Muhammadiyah Surakarta yang sebagian besar populasinya adalah perempuan 48 orang $(70,6 \%)(15)$. Berdasarkan hasil penelitian dan perbandingan penelitian lain, ternyata sebagian besar frekuensi mahasiswa khususnya di Program Studi Pendidikan Ners lebih didominasi dengan mahasiswa putri/perempuan.

Hasil analisis kategori tempat tinggal menggambarkan bahwa, sebagian besar mahasiswa bertempat tinggal tidak dengan orang tua (kos, kontrakan, dan asarama) sebanyak 39 orang $(84,8 \%)$. Pernyataan ini didukung dengan banyaknya penambahan mahasiswa di luar Yogyakarta yang berkuliah di Daerah Istimewa Yogyakarta (16). Berdasarkan hasil penelitian dan artikel terkait, didapatkan bahwa sebagian besar mahasiswa yang berkuliah di Yogyakarta merupakan bukan penduduk asli DI Yogyakarta sehingga mereka lebih memilih untuk bertempat tinggal tidak bersama orang tua (kos, kontrakan, dan asrama).

Tabel 2. Distribusi Variabel Penelitian Mahasiswa Akhir Program Studi Pendidikan Ners Perguruan Tinggi Alma Ata Yogyakarta

\begin{tabular}{lcc}
\hline \multicolumn{1}{c}{ Variabel } & f & $\%$ \\
\hline Mekanisme Koping & & \\
$\quad$ Adaptif & 14 & 30,4 \\
$\quad$ Maladaptif & 32 & 69,6 \\
Depresi & & \\
$\quad$ Minimal & 19 & 41,3 \\
Ringan & 21 & 45,7 \\
Sedang & 6 & 13,0 \\
Total & 46 & 100 \\
\hline
\end{tabular}

Sumber: Data Primer Tahun 2014

Berdasarkan Tabel 2, diketahui bahwa ratarata mahasiswa memiliki mekanisme koping yang maladaptif yaitu sebanyak 32 orang $(69,6 \%)$ dan adaptif sebanyak 14 orang $(30,4 \%)$. Sedangkan ratarata tingkat depresi pada mahasiswa tingkat akhir yaitu mengalami depresi ringan sebanyak 21 orang $(45,7 \%)$, dan nilai terendah pada depresi sedang yaitu 6 orang $(13,0 \%)$.

Mekanisme koping pada mahasiswa tingkat akhir Program Studi Pendidikan Ners Perguruan Tinggi Alma Ata Yogyakarta sebagian besar yang terdeteksi ialah bersifat Maladaptif. Penggunaan mekanisme koping pada remaja akhir dan dewasa muda biasanya didominasi oleh maladaptif disebabkan masih tingginya ego dan kepentingan pribadi yang membuat seseorang mudah terpengaruh akan suatu situasi(12). Hal inilah yang mengakibatkan sebagian besar remaja akhir lebih sering menggunakan mekanisme koping maladaptif. Tetapi dari hasil analisis juga didapatkan bahwa 14 orang menggunakan mekanisme koping adaptif yang berarti keempat belas orang tersebut mampu mengontrol ego dan kepentingan pribadi yang ada pada diri mereka.

Hasil analisis tingkat depresi pada mahasiswa tingkat akhir Program Studi Pendidikan Ners Perguruan Tinggi Alma Ata Yogyakarta didapatkan bahwa sebagian besar mengalami depresi ringan. Umur 18 hingga 24 tahun yang berarti masa perkembangan remaja menuju arah dewasa akan mengakibatkan tingkatan depresi yang signifikan(17). Hal ini dikarnakan mereka akan mulai berfikir untuk 
hidup mandiri sehingga banyak tekanan persepsi diri yang mengakibatkan para mahasiswa ini akan sangat rentan terhadap depresi(18).

Tabel 3. Tabulasi Silang Usia dengan Mekanisme Koping

\begin{tabular}{|c|c|c|c|c|c|c|c|}
\hline \multirow{3}{*}{$\begin{array}{c}\text { Usia } \\
\text { (tahun) }\end{array}$} & \multicolumn{4}{|c|}{ Mekanisme Koping } & \multirow{2}{*}{\multicolumn{2}{|c|}{ Total }} & \multirow{3}{*}{$p$-value } \\
\hline & \multicolumn{2}{|c|}{ Adaptif } & \multicolumn{2}{|c|}{ Maladaptif } & & & \\
\hline & $f$ & $\%$ & $f$ & $\%$ & $f$ & $\%$ & \\
\hline 20 & 1 & 2,2 & 5 & 10,9 & 6 & 13,0 & 0,408 \\
\hline 21 & 10 & 21,7 & 14 & 30,4 & 24 & 52,2 & \\
\hline 22 & 3 & 6,5 & 6 & 13,0 & 9 & 19,6 & \\
\hline 23 & 0 & 0 & 5 & 10,9 & 5 & 10,9 & \\
\hline 24 & 0 & 0 & 1 & 2,2 & 1 & 2,2 & \\
\hline 40 & 0 & 0 & 1 & 2,2 & 1 & 2,2 & \\
\hline Total & 14 & 30,4 & 32 & 69,6 & 46 & 100,0 & \\
\hline
\end{tabular}

Sumber: Data Primer Tahun 2014

Berdasarkan Tabel 3 terlihat bahwa responden yang paling banyak menggunakan mekanisme koping adaptif adalah kelompok usia 21 tahun sebanyak 10 orang $(21,7 \%)$, dan yang paling sedikit adalah usia 20 tahun berjumlah 1 orang $(2,2 \%)$. Untuk mekanisme koping maladaptif paling banyak digunakan kelompok usia 21 tahun sebanyak 14 orang $(30,4 \%)$ dan yang paling sedikit adalah usia 24 tahun sebanyak 1 orang $(2,2 \% \%)$ dan 40 tahun dengan jumlah yang sama yaitu 1 orang $(2,2 \%)$. Hasil hitung uji statistik didapatkan $p$-value 0,408 $(>0,05)$ yang berarti tidak terdapat hubungan yang signifikan antara usia dengan mekanisme koping pada mahasiswa tingkat akhir Program Studi Pendidikan Ners Perguruan Tinggi Alma Ata Yogyakarta. Usia kesiapan pada mahasiswa bukan merupakan salah satu faktor penentu mekanisme koping(13).

Berdasarkan hasil penelitian dan teori, usia pada mahasiswa akhir bukan penentu untuk penggunaan mekanisme koping karna masih banyak faktor lain yang dapat mendukung. Adapun faktor tersebut ialah lingkungan individu, pola fikir, kemampuan adaptasi merupakan faktor utama seseorang dalam penentuan mekanisme koping sehingga mampu untuk mengantisipasi gejala depresi dan stress yang mulai muncul(19).
Berdasarkan Tabel 4, terlihat bahwa responden laki-laki menggunakan rata-rata mekanisme koping maladaptif sebanyak 15 orang $(32,6 \%)$ dan adaptif sebanyak 3 orang $(6,5 \%)$, sedangkan responden perempuan menunjukan rata-rata pengguna mekanisme koping maladaptif sebanyak 17 orang $(37,0 \%)$ dan adaptif sebanyak 11 orang $(23,9 \%)$.

Hasil hitung uji statistik didapatkan $p$-value 0,104 $(>0,05)$ yang berarti tidak terdapat hubungan yang signifikan antara jenis kelamin dengan mekanisme koping pada mahasiswa tingkat akhir Program Studi Pendidikan Ners Perguruan Tinggi Alma Ata Yogyakarta. Jenis kelamin tidak selamanya menjadi faktor penentu mekanisme koping(20).

Berdasarkan hasil penelitian dan teori, jenis kelamin tidak dapat menjadi patokan dalam menentukan mekanisme koping yang digunakan oleh suatu individu, walaupun memang kejadian depresi maupun stress secara tanda dan gejala cenderung lebih banyak dialami oleh wanita, walaupun kenyataannya kasus bunuh diri di Indonesia akibat proses skripsi lebih banyak dilakukan oleh laki-laki, sehingga jenis kelamin memang bukan salah satu faktor penentu penggunaan mekanisme koping(9). Pada tabel memang dapat dilihat bahwa sebagian besar penggunaan mekanisme koping merupakan jenis maladaptif pada laki-laki maupun perempuan, tetapi terdapat pula beberapa orang yang menggunakan mekanisme koping adaptif, secara tidak langsung berarti beberapa orang yang mampu menggunakan mekanisme koping adaptif ini mampu untuk mengendalikan ego dan keinginan induvidu yang ada pada diri mereka.

Berdasarkan Tabel 5, terlihat bahwa reponden yang bertempat tinggal tidak dengan orang tua (kos, kontrakan, asrama) rata-rata menggunakan mekanisme koping maladaptif sebanyak 25 orang $(54,3 \%)$ dan adaptif sebanyak 14 orang $(30,4 \%)$, sedangkan responden yang bertempat tinggal dengan orang tua sebanyak 7 orang dan semuanya menggunakan mekanisme koping maladaptif $(15,2 \%)$.

Hasil hitung uji statistik didapatkan $p$-value $0,057(>0,05)$ yang berarti tidak terdapat hubungan yang signifikan antara tempat tinggal dengan mekanisme koping pada mahasiswa tingkat akhir

Tabel 4. Tabulasi Silang Jenis Kelamin dengan Mekanisme Koping

\begin{tabular}{|c|c|c|c|c|c|c|c|}
\hline \multirow{3}{*}{ Jenis Kelamin } & \multicolumn{4}{|c|}{ Mekanisme Koping } & \multirow{2}{*}{\multicolumn{2}{|c|}{ Total }} & \multirow{3}{*}{ p-value } \\
\hline & \multicolumn{2}{|c|}{ Adaptif } & \multicolumn{2}{|c|}{ Maladaptif } & & & \\
\hline & $f$ & $\%$ & $f$ & $\%$ & $f$ & $\%$ & \\
\hline Laki-laki & 3 & 6,5 & 15 & 32,6 & 18 & 39,1 & \\
\hline Perempuan & 11 & 23,9 & 17 & 37,0 & 28 & 60,9 & 0,104 \\
\hline Total & 14 & 30,4 & 32 & 69,6 & 46 & 100,0 & \\
\hline
\end{tabular}

Sumber: Data Primer Tahun 2014 
Tabel 5. Tabulasi Silang Tempat Tinggal dan Mekanisme Koping

\begin{tabular}{|c|c|c|c|c|c|c|c|}
\hline \multirow{3}{*}{ Tempat Tinggal } & \multicolumn{4}{|c|}{ Mekanisme Koping } & \multirow{2}{*}{\multicolumn{2}{|c|}{ Total }} & \multirow{3}{*}{ p-value } \\
\hline & \multicolumn{2}{|c|}{ Adaptif } & \multicolumn{2}{|c|}{ Maladaptif } & & & \\
\hline & $f$ & $\%$ & $f$ & $\%$ & $f$ & $\%$ & \\
\hline Kos/Kontrakan/Asrama & 14 & 30,4 & 25 & 54,3 & 39 & 84,8 & \\
\hline Orang Tua & 0 & 0 & 7 & 15,2 & 7 & 15,2 & 0,057 \\
\hline Total & 14 & 30,4 & 32 & 69,6 & 46 & 100,0 & \\
\hline
\end{tabular}

Sumber: Data Primer Tahun 2014

Program Studi Pendidikan Ners Perguruan Tinggi Alma Ata Yogyakarta. Tempat tinggal merupakan tempat penentuan mekanisme koping yang tepat disebabkan adanya dukungan keluarga(14).

Berdasarkan hasil penelitian dan perbandingan dengan penelitian Indra ditekankan bahwa tempat tinggal memang dapat menjadi faktor penentu penggunaan mekanisme koping pada mahasiswa tingkat akhir, hal ini mengingat lingkungan bukan merupakan salah satu hal yang dapat menentukan penggunaan mekanisme koping seseorang, sebab justru yang ditekankan secara jelas bahwa, dukungan orang tua dan masyarakat mau itu teman, keluarga, dan masyarakat yang dapat membentuk mekanisme seseorang apakah akan bersifat adaptif ataupun maladaptif(14). Lingkungan merupakan cover atau sampul dalam suatu penentuan mekanisme koping, tetapi hal terpenting yang merupakan pencetus terbentuknya mekanisme koping ialah satu kesatuan yang ada didalam lingkungan itu sendiri sehingga seseorang dapat terhindar dari stress dan depresi(21).

Berdasarkan Tabel 6, diketahui bahwa mayoritas responden yang menggunakan mekanisme koping adaptif mengalami minimal depresi sebanyak 14 orang (30,4\%), dan rata-rata responden yang menggunakan mekanisme koping maladaptif mengalami depresi ringan sebanyak 21 orang (45,7\%).

Hasil hitung uji statistik didapatkan $p$-value 0,000 yang berarti terdapat hubungan yang signifikan antara mekanisme koping dengan tingkat depresi pada mahasiswa tingkat akhir Program Studi Pendidikan Ners Perguruan Tinggi Alma Ata Yogyakarta.
Mekanisme koping merupakan bentuk antisipasi normal setiap manusia untuk mengantisipasi masalah bersifat psikis terutama stress dan depresi, sehingga semakin baik (adaptif) mekanisme koping yang digunakan seseorang maka semakin kecil kemungkinan stress atau depresi yang akan dialami, tetapi sebaliknya semakin jelek (maladaptif) mekanisme koping seseorang, maka semakin besar pula resiko kejadian stress maupun depresi(9). Mekanisme koping seperti sebuah benteng yang bekerja keras untuk melindungi seseorang dari serangan stress atau depresi(19). Fakta yang tersedia dan teori yang ada dapat membuat kita menarik sebuah simpulan yaitu mekanisme koping merupakan hal dasar yang dapat kita terapkan untuk dapat mengetahui apakah seseorang mengalami stress atau depresi. Pada Tabel 4 juga terlihat bahwa ada 14 orang yang menggunakan mekanisme koping adaptif dan mengalami derpresi ringan, ini berarti mekanisme koping dapat meminimalisir tingkatan depresi sebaliknya pada kolom maladaptif hampir sebagian besar mahasiswanya mengalami depresi ringan dan hanya 5 orang yang mengalami minimal depresi.

\section{SIMPULAN DAN SARAN}

Karakteristik depresi responden dimana sebagian besar ialah tergolong depresi ringan sebanyak 21 orang $(45,7 \%)$, minimal depresi 19 orang $(41,3 \%)$ dan depresi sedang 6 orang $(13,0 \%)$. Karakteristik mekanisme koping yang digunakan oleh mahasiswa tingkat akhir sebagian

Tabel 6. Hubungan antara Mekanisme Koping dengan Tingkat Depresi pada Mahasiswa Tingkat Akhir Program Studi Pendidikan Ners Perguruan Tinggi Alma Ata Yogyakarta

\begin{tabular}{lccccccc}
\hline \multirow{2}{*}{ Tingkat Depresi } & \multicolumn{3}{c}{ Mekanisme Koping } & \multicolumn{2}{c}{ Total } & \multirow{2}{*}{ p-value } \\
\cline { 2 - 6 } & \multicolumn{2}{c}{ Adaptif } & \multicolumn{2}{c}{ Maladaptif } & & \\
\cline { 2 - 6 } & $\mathbf{f}$ & $\%$ & $\mathbf{f}$ & $\%$ & $\mathbf{f}$ & $\%$ & \\
\hline Minimal Depresi & 14 & 30,4 & 5 & 10,9 & 19 & 41,3 & \\
Depresi Ringan & 0 & 0 & 21 & 45,7 & 21 & 45,7 & 0,000 \\
Depresi Sedang & 0 & 0 & 6 & 13,0 & 6 & 13,0 & \\
Total & 14 & 30,4 & 32 & 69,6 & 46 & 100,0 & \\
\hline
\end{tabular}

Sumber: Data Primer Tahun 2014 
besar ialah maladaptif sebanyak 32 orang $(69,6 \%)$ dan adaptif 14 orang $(30,4 \%)$. Tidak ada hubungan yang signifikan antara mekanisme koping dengan usia dengan $p$-value 0,408 . Jenis kelamin tidak ada hubungannya yang signifikan antara jenis kelamin dengan mekanisme koping dengan $p$-value $=0,104$ $(>0,103)$. Tidak ada hubungan yang signifikan antara tempat tinggal dan mekanisme koping tempat tinggal ditandai dengan $p$-value $=0,057$ $(>0,05)$. Ada hubungan yang bermakna antara mekanisme koping dengan tingkat depresi pada mahasiswa tingkat akhir Program Studi Pendidikan Ners Perguruan Tinggi Alma Ata dengan $p$-value $0,000(p<0,05)$.

Saran bagi mahasiswa diharapkan mampu mendeteksi mekanisme koping yang digunakan untuk mengetahui tingkatan depresi yang dialami saat memasuki semester akhir perkuliahan. Bagi instansi pendidikan terkait mampu meningkatkan sumber daya yang ada dan mengoptimalkan perannya terutama dalam bidang konseling untuk mengetahui masalah yang timbul akibat proses skripsi.

\section{RUJUKAN}

1. Monk FJ, et al. Psikologi Perkembangan: Pengantar dalam Berbagai Bagiannya. Yogyakarta: Gajah Mada University Press; 2002.

2. Panjaitan YVZ. Hubungan Antara Optimisme dengan Stress pada Mahasiswa yang sedang Menyusun Skripsi. Semarang: Universitas Katolik Soegijapranta; 2014.

3. U.S. Departement of Heatlh and Human Services. Transforming the Understanding and Treatment of Mental IIInesses. U.S: National Institute of Mental Health; 2012.

4. France L, Sita PA. WHO: 350 Juta Penduduk Dunia Depresi [internet]. 2012 [cited 2014 Nov 19]. Available from: http://www.tempo.co/read/ news/2012/10/09/06 0434734/WHO-350-JutaPenduduk-Dunia-Depresi.

5. KEMENKES RI. Kesehatan Jiwa Sebagai Prioritas Global [internet]. 2009 [cited 2014 Nov 19]. Available from: http://www.depkes. go.id/article/print/394/ kesehatan-jiwa-sebagaiprioritas-global.html.

6. Muhardiansyah Y. Diduga Stress Gara-Gara Skripsi, Mahasiswa USU Gantung Diri [internet]. 2014 [cited 2014 Nov 19]. Available from: http:// www.merdeka. com/peristiwa/diduga-stress-garagara-skripsi-mahasiswa-usu-gantung-diri.html.
7. Riset Kesehatan Dasar. Badan Penelitian Pengembangan Kesehatan. Jakarta: Departemen Kesehatan R.I; 2007.

8. Robbi. Di Indonesia, Pelayanan Kesehatan Jiwa Masih Minim [internet]. 2014 [cited 2014 Nov 19]. Available from: http://harinterbit.com/m/wlcome/ read /2014/06/21/4063/0/29/Di-IndonesiaPelayanan-Kesehatan-Jiwa-Masih-Minim.

9. Azizah LM. Keperawatan Jiwa Aplikasi Praktik Klinik. Yogyakarta: Graha IImu; 2011.

10. Keliat, Budi A, et al. Proses Keperawatan Masalah Keperawatan Kesehatan Jiwa. 2nd ed. Jakarta: EGC; 2005.

11. Stuart, Sundeen. Buku Saku Keperawatan Jiwa. 3rd ed. Jakarta: EGC; 2006.

12. Untari TD. Faktor-Faktor yang Berhubungan dengan Terjadinya Depresi pada Mahasiswa Tingkat Akhir Fakultas Kesehatan Masyarakat Universitas Diponogoro Semarang Tahun 2005. Semarang: Universitas Diponogoro; 2005.

13. Garry GM. Handbook Psychological Assesment. 5th ed. Yogyakarta: Pustaka Pelajar; 2010.

14. Indra SF. Perbedaan Mekanisme Koping Mahasiswa Baru FKM UI Reguler 2011 yang Tinggal Bersama Orang Tua dengan yang Tinggal Tidak Bersama Orang Tua. Jakarta: Universitas Indonesia; 2012.

15. Beauty S, Arif W. Hubungan antar Peran Dosen dengan Kecemasan Mahasiswa Keperawatan dalam Menghadapi Tugas Akhir Skripsi di Fakultas IImu Kesehatan UMS. Surakarta: Universitas Muhammadiyah Surakarta; 2012.

16. Akhmad C. Jumlah Mahasiswa Baru di Yogyakarta Meningkat Signifikan [internet]. 2012 [cited 2014 Jan 14]. Available from: http://www.republika.co.id/berita /pendidikan/beritapendidikan/12/09/03/m9s2mdjumlah-mahasiswa-baru-di-yogya-meningkatsiginifikan.

17. Davison GC, Naela JM, Kring AM. Psikologi Abnormal. 9th ed. Jakarta: PT Raja Grafindo Persada; 2006.

18. Maramis WF. Catatan IImu Kedokteran Jiwa. 2nd ed. Surabaya: Airlangga University Press; 2010.

19. Weiten W, et al. Psychology Apllied ti Modern Life. 10th ed. USA: Cengage Learning; 2012.

20. Coper, Erin. Depression Among African American Female College Students Explanatory Factor Analysis of the Beck Depression Inventory II. ProQuest Dissertations and Thesis; 2010.

21. Sarafino EP. Health Psychology: Biopsychosocial Interaction. USA: Jhon Willey and Sons; 2008. 